\title{
Perinatal outcome in pregnant females at term having low amniotic fluid index.
}

\footnotetext{
1. FCPS

Associate Professor Obs \& Gynae Independent Medical College, Faisalabad.

2. MBBS

Post Graduate Trainee Independent Medical College, Faisalabad.
}

Correspondence Address: Dr. Nadia Sharif Department of Obs \& Gynae Independent Medical College, Faisalabad

naadiasharif@hotmail.com

Article received on: 02/06/2021

Accepted for publication: 05/08/2021

\begin{abstract}
Nadia Sharif', Ayesha Qasim²
ABSTRACT... Objectives: To determine the frequency of perinatal outcome in pregnant females at term having low amniotic fluid index. Study Design: Descriptive, Case Series study. Setting: Department of Obstetrics \& Gynecology, Independent University Hospital, Faisalabad. Period: $1^{\text {st }}$ October 2019 to $31^{\text {st }}$ March 2020. Materials \& Methods: A total of 90 women having singleton pregnancy with cephalic presentation having $37-40$ weeks of gestation with $\mathrm{AFI}<8 \mathrm{~cm}$, 20 to 35 years of age were included. Patients with multiple pregnancy, ruptured membrane, fetal anomaly, gestational diabetes and Rh Incompatibility were excluded. Cesarean delivery, meconium stained liquor, low birth weight, NICU admission and APGAR score $<7$ at 5 min were assessed by consultant gynecologist. Results: Age range in this study was from 20 to 35 years with mean age of $28.92 \pm 4.45$ years. Majority of the patients $43(47.77 \%)$ were between 31 to 35 years of age. Mean gestational age was $38.31 \pm 1.20$ weeks. Mean parity was $2.72 \pm 1.02$. In this study, frequency of perinatal outcome in pregnant females at term having low amniotic fluid index was as follows; cesarean section was performed in $60(66.67 \%)$, low birth weight was observed in $58(64.44 \%)$ patients, APGAR score $<7$ at 5 minutes in $56(62.22 \%)$, meconium stained liquor in $24(26.67 \%)$ and NICU admission in 17 (18.89\%) patients. Conclusion: This study concluded that proper antenatal monitoring and management should be done in these high risk patients in order to reduce the morbidity and mortality of the fetus.
\end{abstract}

Key words: Cesarean Section, Low Amniotic Fluid Index, Low Birth Weight.

Article Citation: Sharif N, Qasim A. Perinatal outcome in pregnant females at term having low amniotic fluid index. Professional Med J 2021; 28(9):1358-1364. https://doi.org/10.29309/TPMJ/2021.28.09.6760

\section{INTRODUCTION}

Amniotic fluid assessment is an integral part of the antenatal evaluation of pregnancies at risk for an adverse pregnancy outcome especially in the third trimester. Detecting the fetus at risk for in utero damage or death, quantifying, and balancing the fetal risk against the risk of neonatal complications from immaturity, and determining the optimal time and mode of intervention is the cornerstone of modern day obstetrics care and perinatal medicine. ${ }^{1}$ Assessment of amniotic fluid volume by ultra sonography is more reliable. ${ }^{2}$

Amniotic fluid index (AFI) is the preferred method of amniotic fluid measurement in pregnancy although single deepest pocket is used in pregnancies. For measuring AFI the uterus divided into four equal quadrants. AFI is the sum of deepest pocket from each quadrant. The normal range of $\mathrm{AFI}$ is between $5-24 \mathrm{~cm}$ while any value above $24 \mathrm{~cm}$ will be considered as Hydraminios and with value below $5 \mathrm{~cm}$ will be indicated as Oligohydraminios. ${ }^{3}$

Reduced amniotic fluid index (AFI) is associated with adverse effects such as meconium staining, congenital anomalies, growth retardation, dysmaturity, and fetal asphyxia." However, some studies show that AFI is a poor predictor of adverse perinatal outcome and should not be the only parameter for predicting perinatal outcome. ${ }^{4}$

Amniotic fluid plays a major role in the fetal growth and development. It provides the fetus with a protective low resistance environment suitable for growth and development. It provides a cushion against the constricting confines of the gravid uterus, allowing the fetus room for the movement and growth and protecting it from external trauma. It prevents compression of the umbilical 
cord and thus protects the fetus from vascular and nutritional compromise..$^{5,6}$ The abnormalities of the fluid volume can thus interfere directly with the fetal development or may be an indirect sign of underlying disorder such as fetal hypoxia, neural tube defect or gastrointestinal obstruction. Amniotic fluid index (AFI) of $<5 \mathrm{~cm}$ defines oligohydramnios.

Literature shows variability of perinatal outcome associated with low AFI. Cesarean delivery was observed in $74 \%^{7}$, meconium stained liquor was found in $40.62 \%^{8}$, low birth weight was noted in $64 \%$, APGAR score $<7$ at 5 min was found in $34 \%{ }^{6}$ and NICU admission was noted in $92 \%$ patients of low AFI. ${ }^{9}$ In other studies, cesarean delivery was observed in $36 \%$, meconium stained liquor was found in $12 \%{ }^{10}$, low birth weight was noted in $32 \%{ }^{11}$, APGAR score $<7$ at 5 min was found in $4 \%{ }^{9}$ and NICU admission was noted in $3.12 \%$ patients of low AFI. ${ }^{12}$

As there is controversy in literature regarding the relation of adverse perinatal outcome and low AFI. So, I have conduct this study to assess the frequency of adverse perinatal outcome in females having low amniotic fluid index.

The amniotic fluid that bathes the fetus is necessary for its proper growth and development. It cushions the fetus from physical trauma, permits fetal lung growth, and provides a barrier against infection. Normal amniotic fluid volume varies. The average volume increases with gestational age, peaking at $800-1000 \mathrm{~mL}$, which coincides with 36-37 weeks' gestation. An abnormally high level of amniotic fluid, polyhydramnios, alerts the clinician to possible fetal anomalies. Inadequate volume of amniotic fluid, oligohydramnios, results in poor development of the lung tissue and can lead to fetal death.

The objective of the study was to determine the perinatal outcome in pregnant females at term having low amniotic fluid index.

\section{MATERIAL \& METHODS}

This was a descriptive case series conducted at independent university hospital, Faisalabad, from October 2019 to March 2020. The study was approved by institutional ethical committee. The sampling was done by Non-probability, consecutive sampling. The sample size was calculating by using by using WHO sample size calculator $\mathrm{P}=34 \%^{6}$, Absolute precision required $=10 \%$, Confidence level $=95 \%$, ample size $=$ 90.

Following was the inclusion and exclusion criteria:

\section{Inclusion Criteria}

Females age ranges from 20-35 years.

Females having singleton pregnancy with cephalic presentation having 37-40 weeks of gestation.

Females having AFI $<8 \mathrm{~cm}$.

Females having intact membranes.

\section{Exclusion Criteria}

Females having

Ruptured membranes

Fetal anamoly

Gestational diabetes

Rh incompatibility

Multiple pregnancies.

After taking approval from hospital ethical committee, patients coming through OPD fulfilling the inclusion criteria were enrolled and informed consent was taken. Cesarean delivery, meconium stained liquor, low birth weight, NICU admission and APGAR score $<7$ at 5 min were assessed by consultant Obstetrician. All the information was collected on a specially designed proforma.

The data was entered and analyzed in SPSS version 22. Descriptive statistics including mean and standard deviation of numerical values like age, parity and gestational age were calculated. Frequency and percentage were calculated for all qualitative variables like cesarean delivery, meconium stained liquor, low birth weight, NICU admission and APGAR score $<7$ at 5 min.

Effect modifiers like age, parity and gestational age were controlled by stratification. Post stratification chi-square test was applied. P-value $<0.05$ was considered significant. 


\section{OPERATIONAL DEFINITIONS}

Low amniotic fluid index: Amniotic fluid index < $8 \mathrm{~cm}$ on ultrasound was said to be low amniotic fluid index.

Pregnant females at term: Females having 3740 weeks of gestation on ultrasound.

Perinatal outcome: It was assessed in terms of

Cesarean section: Cesarean section is a surgical procedure in which fetus was delivered through an incision in the mother's abdomen and uterus.

Meconium stained liquor: After artificial rupture of membrane, light to dark green or brown color of amniotic fluid was said to have meconium stained liquor.

Low birth weight: It was the weight of baby $<2.5$ $\mathrm{kg}$ at birth.

NICU admission: It was the admission of baby to neonatal intensive care unit within 24 hours of birth.

APGAR score $<\mathbf{7}$ at $\mathbf{5}$ min: It was assessed after 5 minutes of birth as follows:

\begin{tabular}{|l|l|l|l|l|}
\hline & \multicolumn{1}{|c|}{ Indicator } & 0 Point & \multicolumn{1}{|c|}{$\mathbf{1}$ Point } & \multicolumn{1}{|c|}{ 2 Point } \\
\hline $\mathbf{A}$ & $\begin{array}{l}\text { Activity } \\
\text { (muscle tone) }\end{array}$ & Absent & $\begin{array}{l}\text { Flexed } \\
\text { arms \& legs }\end{array}$ & Active \\
\hline $\mathbf{P}$ & Pulse & Absent & $\begin{array}{l}\text { Below 100 } \\
\text { bpm }\end{array}$ & $\begin{array}{l}\text { Over 100 } \\
\text { bpm }\end{array}$ \\
\hline $\mathbf{G}$ & $\begin{array}{l}\text { Grimace } \\
\text { (reflex } \\
\text { irritability) }\end{array}$ & Floppy & $\begin{array}{l}\text { Minimal } \\
\text { response to } \\
\text { stimulation }\end{array}$ & $\begin{array}{l}\text { Prompt } \\
\text { response } \\
\text { to } \\
\text { stimulation }\end{array}$ \\
\hline $\mathbf{A}$ & Appearance & $\begin{array}{l}\text { Blue, } \\
\text { pale }\end{array}$ & $\begin{array}{l}\text { Pink } \\
\text { body, blue } \\
\text { extremities }\end{array}$ & Pink \\
\hline $\mathbf{R}$ & Respiration & Absent & $\begin{array}{l}\text { Slow and } \\
\text { irregular }\end{array}$ & $\begin{array}{l}\text { Vigorous } \\
\text { cry }\end{array}$ \\
\hline
\end{tabular}

\section{RESULTS}

Age range in this study was from 20 to 35 years with mean age of $28.92+4.45$ years. Majority of the patients $43(47.77 \%)$ were between 31 to 35 years of age as shown in Table-l. Mean gestational age was $38.31+1.20$ weeks (Table-II). Mean parity was $2.72+1.02$ (Table-III).

In this study, frequency of perinatal outcome in pregnant females at term having low amniotic fluid index was as follows; cesarean section was found in 60 (66.67\%), low birth weight in 58 (64.44\%) patients, APGAR score $<7$ at 5 minutes in $56(62.22 \%)$, meconium stained liquor in 24 (26.67\%) and NICU admission in 17 (18.89\%) patients as shown in Table-IV.

Stratification of the cesarean section, APGAR score $<7$ at 5 minutes, meconium stained liquor and NICU admission with respect to age is shown in Table V, VI, VII, VIII respectively. Stratification of low birth weight and NICU admission with respect to gestational age is shown in Table IX \& X.

\begin{tabular}{|c|c|}
\hline \multicolumn{1}{|c|}{ Age (in years) } & No. of Patients \\
\hline $20-25$ & $24(26.67 \%)$ \\
\hline $26-30$ & $23(25.56 \%)$ \\
\hline $31-35$ & $43(47.77 \%)$ \\
\hline
\end{tabular}

Table-I. Age distribution of patients $(n=90)$ Age Mean \pm 4.45 years

\begin{tabular}{|l|c|}
\hline Gestation Age (weeks) & No. of Patients \\
\hline $37-38$ weeks & $53(58.89 \%)$ \\
\hline $39-40$ weeks & $37(41.11 \%)$ \\
\hline Mean \pm SD & $38.31 \pm 1.20$ \\
\hline
\end{tabular}

Table-II. Distribution of patients according to gestational age $(n=90)$

\begin{tabular}{|c|c|}
\hline Parity & No. of Patients \\
\hline $0-2$ & 72 (80.0\%) \\
\hline $3-5$ & 18 (20.0\%) \\
\hline
\end{tabular}

Table-III. Distribution of patients according to parity $(n=90)$

\begin{tabular}{|l|c|c|}
\hline \multicolumn{1}{|c|}{$\begin{array}{c}\text { Fetomaternal } \\
\text { Outcome }\end{array}$} & \multicolumn{2}{c|}{ Frequency (\%) } \\
\hline Cesarean section & $60(66.67 \%)$ & $30(33.33 \%)$ \\
\hline Low birth weight & $58(64.44 \%)$ & $32(35.56 \%)$ \\
\hline $\begin{array}{l}\text { APGAR score <7 at } 5 \\
\text { minutes }\end{array}$ & $56(62.22 \%)$ & $34(37.78 \%)$ \\
\hline NICU admission & $17(18.89 \%)$ & $73(81.11 \%)$ \\
\hline $\begin{array}{l}\text { Meconium stained } \\
\text { liquor }\end{array}$ & $24(26.67 \%)$ & $66(73.33 \%)$ \\
\hline
\end{tabular}

Table-IV. Frequency of perinatal outcome in pregnant females at term having low amniotic fluid index 


\begin{tabular}{|l|c|c|c|}
\hline \multirow{2}{*}{$\begin{array}{c}\text { Age } \\
\text { (in years) }\end{array}$} & \multicolumn{2}{|c|}{ Cesarean Section } & \multirow{2}{*}{ P-Value } \\
\hline $20-25$ & Yes & No & \\
\hline $26-30$ & 14 & 10 & \\
\hline $31-35$ & 18 & 05 & 0.335 \\
\hline
\end{tabular}

Table-V. Stratification of the cesarean section with respect to age

\begin{tabular}{|l|c|c|c|}
\hline \multirow{2}{*}{$\begin{array}{c}\text { Age } \\
\text { (in years) }\end{array}$} & \multicolumn{2}{|c|}{ APGAR Score $<\mathbf{7}$ at $\mathbf{5}$ min } & P-Value \\
\hline $20-25$ & Yes & No & \\
\hline $26-30$ & 13 & 11 & \\
\hline $31-35$ & 20 & 03 & 0.018 \\
\hline
\end{tabular}

Table-IV. Stratification of the APGAR score $<7$ at 5 min with respect to age

\begin{tabular}{|c|c|c|c|}
\hline \multirow{2}{*}{$\begin{array}{c}\text { Age } \\
\text { (in years) }\end{array}$} & \multicolumn{2}{|c|}{ Meconium Stained Liquor } & \multirow{2}{*}{ P-Value } \\
\hline $20-25$ & 03 & 21 & \\
\hline $26-30$ & 07 & 16 & 0.183 \\
\hline $31-35$ & 14 & 29 & \\
\hline
\end{tabular}

Table-VII. Stratification of the meconium stained liquor with respect to age

\begin{tabular}{|l|c|c|c|}
\hline \multirow{2}{*}{$\begin{array}{c}\text { Age } \\
\text { (in years) }\end{array}$} & \multicolumn{2}{|c|}{ NICR Admission } & \multirow{2}{*}{ P-Value } \\
\hline $20-25$ & Yes & No & \\
\hline $26-30$ & 02 & 22 & \\
\hline $31-35$ & 03 & 20 & 0.103 \\
\hline
\end{tabular}

Table-VIII. Stratification of the meconium stained liquor with respect to age

\begin{tabular}{|c|c|c|c|}
\hline \multirow{2}{*}{$\begin{array}{c}\text { GA } \\
\text { (Weeks) }\end{array}$} & \multicolumn{2}{|c|}{ Low Birth Weight } & \multirow{2}{*}{ P-Value } \\
\hline $37-38$ & Yes & No & \\
\hline $39-40$ & 33 & 20 & \multirow{2}{*}{0.605} \\
\hline
\end{tabular}

Table-IX. Stratification of the low birth weight with respect to gestational age

\begin{tabular}{|l|l|l|l|}
\hline \multicolumn{1}{|c|}{$\begin{array}{c}\text { GA } \\
\text { (Weeks) }\end{array}$} & \multicolumn{2}{|c|}{ NICU Admission } & \multirow{2}{*}{ P-Value } \\
\hline $37-38$ & Yes & No & \\
\hline $39-40$ & 33 & 42 & \multirow{2}{*}{0.588} \\
\hline
\end{tabular}

Table-X. Stratification of the NICU admission with respect to gestational age

\section{DISCUSSION}

Amniotic fluid assessment is an essential part of evaluation of fetus health in terms of fetal distress, meconium aspiration, caesarean and fetal mortality. ${ }^{13}$ The assessment of amniotic fluid volume is very crucial for the survival of the fetus and the Amniotic Fluid Index (AFI) is the most common way for the estimation of amniotic fluid volume which is performed by ultrasound method. ${ }^{14,15}$ Studies have revealed that AFI is an accurate criterion for estimating adequate placental function. ${ }^{16}$ Amniotic fluid volume varies with gestational age, rising to a plateau between 22-39 weeks of gestation and reaching 700 and $800 \mathrm{ml}$, which correspond to an AFI of 14-15 $\mathrm{cm} .{ }^{17,18}$ Any decrease or increase in the volume of amniotic fluid leads to pregnancy complications.

In spite of different views on borderline AFI in different studies, there are, also, different views about its function and influence on maternal and fetal complications and medical care for fetus health. In most reported studies, the pregnancies with borderline AFI of $5-10 \mathrm{~cm}$ have shown outcomes such as non-reactive non-stress tests, fetal heart rate (FHR) deceleration, meconium aspiration, immediate caesarean delivery, low APGAR score, LBW, NICU admission and SGA in comparison with control subjects with normal amniotic fluid level $(8.1-18 \mathrm{~cm})^{19-26}$, Also the low amniotic index may increase the operative delivery rate.

Also, according to Luo et al the pregnancy outcomes of a borderline versus normal AFI suggested no difference in the incidence of fetal distress or neonatal mortality, but the rate of caesarean delivery in borderline AFI was reported higher than the rate in normal cases. They evaluated 196 trails of labor with a borderline AFI $(5.1-8)$ and 200 women with normal AFI (8.1-18). ${ }^{27}$ Meanwhile, in another study, oligohydramniosis was shown to be associated with pregnancy complications but the diminished amniotic fluid volume doesn't seem to have any noticeable effect on anticipating the outcomes. ${ }^{28}$

In my study, frequency of perinatal outcome in pregnant females at term having low amniotic fluid index was as follows; cesarean section was found in 60 (66.67\%), low birth weight in 58 (64.44\%) patients, APGAR score $<7$ at 5 minutes in 56 (62.22\%), meconium stained liquor in 24 (26.67\%) and NICU admission in 17 (18.89\%) patients. In another study, the caesarean section rate in oligohydramnios was $68 \%$ as compared to $28 \%$ 
in the control group. The incidence of meconium stained liquor in the oligohydramnios group was $32 \%$, compared with $18 \%$ in the control group, APGAR score $<7$ at 5 minutes was $14 \%$ versus $4 \%$ and NICU admission was $14 \%$ versus $4 \%{ }^{29}$ In Al Bayatti study, the caesarean section rate in oligohydramnios was $27 \%$ as compared to $13 \%$ in the control group. The incidence of meconium stained liquor in the oligohydramnios group was $42 \%$, compared with $16 \%$ in the control group, APGAR score $<7$ at 5 minutes was $16 \%$ versus $3 \%$ and NICU admission was $16 \%$ versus $3 \% .{ }^{30}$

Study by Casey $\mathrm{B}$ et $\mathrm{al}^{31}$ found that, there was increased rate of induction of labour (42\%) and caesarean section (32\%) in oligohydramnios cases. Jun Zhang et $\mathrm{al}^{32}$ found that, the overall caesarean delivery rates were similar between women with oligohydramnios and the controls (24\% vs. $19 \%$ ). Golan A et $\mathrm{al}^{33}$ et al. found that, the caesarean section was performed in $35.2 \%$ of pregnancies. Oligohydramnios is associated with increased maternal and foetal morbidities. The perinatal morbidity and mortality is due to foetal distress, low APGAR scores and meconium aspiration syndrome in the foetus. ${ }^{34-36}$

Literature shows variablilty of perinatal outcome associated with low AFI. Cesarean delivery was observed in $74 \%$ meconium stained liquor was found in $40.62 \%$, low birth weight was noted in $64 \%$, APGAR score $<7$ at 5 min was found in $34 \%$ and NICU admission was noted in $92 \%$ patients of low AFI.

In the study by Magann et al. meconium stained amniotic fluid was not different between the groups. ${ }^{37}$ In study by Nargis et al meconium stained liquor was seen in $44 \%$ of the women with low AFI $(<5 \mathrm{~cm})$ as compared to present study where $12 \%$ had meconium stained liquor. ${ }^{38}$ Ahmad et $\mathrm{al}^{39}$ also found no difference in the low APGAR score at 5 minutes in the two groups. Ahmad et al observed that oligohydroamnios group when compared with control group had significantly lower birth weight babies and they were delivered at a significant earlier gestation due to iatrogenic preterm delivery via induction of labor or caesarean sections as compared to control group. ${ }^{40}$

In a prospective comparative study ${ }^{41}$ included a total of 100 women with singleton term pregnancy with cephalic presentation, divided into two groups of 50 each. Women in Group 1 had amniotic fluid index $<5 \mathrm{~cm}$ and in Group 2, had AFI from $6-20 \mathrm{~cm}$. An AFI $<5 \mathrm{~cm}$ was associated with significant high rate of induction of labor $(p<0.001)$, caesarean section $(p=0.04)$ and fetal distress $(p<0.05)$. Meconium-stained liquor $(p=0.76)$, Apgar score less than seven at 5 minutes $(p=0.307)$, low birth weight $(p=0.130)$ or NICU admission $(p=1)$ were comparable in the two groups. ${ }^{42}$

Another study showed significantly higher rate (65.5\%) of low birth weight resulting from the low AFI. The APGAR score less than 7 in 5 minute was significantly higher in severe oligohydramnios group and majority of the neonate experienced complications like RDS (13\%), meconeum aspiration (21\%) with admission in neonatal ward (54\%). Low AFI has poorer prognosis to some extent with maternal as well as fetal outcome. It is responsible for a significantly higher rate of caesarean section and also associated with low birth rate along with low APGAR score and increase in neonatal complications.

\section{CONCLUSION}

This study concluded that frequency of perinatal outcome in pregnant females at term having low amniotic fluid index was as follows; cesarean section was found in $66.67 \%$, low birth weight in $64.44 \%$ patients, APGAR score $<7$ at 5 minutes in $62.22 \%$, meconium stained liquor in $26.67 \%$ and NICU admission in $18.89 \%$ patients. So, we recommend that proper antenatal monitoring and management should be done in these high risk patients in order to reduce the morbidity and mortality of the fetus.

\section{Copyright@ 05 Aug, 2021.}

\section{REFERENCES}

1. Madaan S, Mendiratta SL, Jain PK, Mittal M. Amniotic fluid index and its correlation with fetal growth and perinatal outcome. J Fetal Med. 2015; 2(2):61-7. 
2. Gaikwad PR, Oswal MS, Gandhewar MR, Bhatiyani BR. Perinatal outcome in oligohydramnios and borderline amniotic fluid index: A comparative study. Int J Repord Contracept Obstet Gynecol. 2016; 5:19648.

3. Jamal A, Kazemi M, Marsoosi V, Eslamian L. Adverse perinatal outcomes in borderline amniotic fluid index. Int J Repord Biomed (Yazd). 2016; 14:705-8.

4. Bachhav $A A$, Waikar M. Low amniotic fluid index at term as a predictor of adverse perinatal outcome. $J$ Obstet Gynaecol India. 2014; 64(2):120-3.

5. Rathod S, Samal SK. Evaluation of maternal and perinatal outcomes of induction in borderline oligohydramnios at term. J Clin Diagn Res. 2017; 11(9):QC05-7.

6. Rezaie Kahkhaie K, Keikha F, Rezaie Keikhaie K, Abdollahimohammad A, Salehin S. Perinatal outcome after diagnosis of oligohydramnios at term. Iran Red Crescent Med J. 2014; 16(5):e11772.

7. Thobbi VA, Sabahath S. A study of perinatal outcome in patients with low amniotic fluid index (AFI). Al Ameen J Med Sci. 2017; 10(2):119-23.

8. Rosati P, Guariglia L, Cavaliere AF, Ciliberti P, Buongiorno $S$, Ciardulli $A$, et al. A comparison between amniotic fluid index and the single deepest vertical pocket technique in predicting adverse outcome in prolonged pregnancy. J Prenat Med. 201 5; 9(1-2):125 .

9. Bhagat $M$, Chawla I. Correlation of amniotic fluid index with perinatal outcome. J Obstet Gynaecol India. 2014; 64:32-5.

10. Singhal SR, Gupta R, Sen J. Low amniotic fluid index as a predictor of adverse perinatal outcome - an Indian perspective. Clinics Mother Child Health. 2015; 12:201.

11. Panda S, Jayalakshmi M, Kumari GS, Mahalakshami G, Srujan $Y$, Anusha V. Oligoamnios and perinatal outcome. J Obstet Gynaecol India. 2017; 67:104-8.

12. Regnault TR, Friedman JE, Wilkening RB, Anthony RV, Hay WW, Jr. Fetoplacental transport and utilization of amino acids in IUGR - a review. Placenta. 2005 Apr; 26 Suppl A: S52-62.

13. Ali HS. Assessment of amniotic fluid index in normal pregnancy at a tertiary care hospital setting. J Ayub Med Coll Abbottabad. 2009; 21:149-151.

14. Karim R, Jabeen S, Pervaiz F, Wahab S, Yasmeen S, Raees M. Decreased amniotic fluid index and adverse pregnancy outcome at term. JPMI. 2010; 4:307-311.
15. Voxman EG, Tran S, Wing DA. Low amniotic fluid index as a predictor of adverse perinatal outcome. $J$ Perinatol. 2002; 22:282-185.

16. Pankaj D, Purvi P, Anjali G. Decrease of amniotic fluid index in low- risk pregnancy. Any significance? J Obstet Gynecol Ind. 2004; 54:464-466.

17. Magann EF, Chauhan SP, Bofill JA, Martin JN Jr. Comparability of the amniotic fluid index and single deepest pocket measurements in clinical practice. Aust N Z J Obstet Gynaecol. 2003; 43:75-77.

18. Anderson D, Yang Q, Hohimer A. Faber J, Gi Raud $\mathrm{G}$. Davi SL. Int $\mathbf{r}$ amembranous absorption rate is unaffected by changes in amniotic fluid composition. Am J Physiol Renal Physiol. 2005:288:964—968.

19. Phelan JP, Smith CV, Broussard P, Small M. Amniotic fluid volume assessment with the four-quadrant technique at 36-42 weeks' gestation. J Reprod Med. $1987 ; 32: 540-542$.

20. Rutherford SE, Phelan JP, Smith CV, Jacobs N. The 4 quadrant assessment of amniotic fluid volume: An adjunct to antepartum fetal heart rate testing. Obstet Gynecol. 1987; 70:353-356.

21. Kwon JY, Kwon HS, Kim YH, Park YW. Abnormal Doppler velocimetry is related to adverse pregnancy outcome for borderline amniotic fluid index in the third trimester. J Obstet Gynecol Res. 2006; 32:545549 .

22. Haas DM, Magann EF. External cephalic version with an amniotic fluid index <or $=10$ : A systematic review. J Matern Fetal Neonatal Med. 2005; 18:249-252.

23. Gumus II, Koktener A, Turhan NO. Perinatal outcome of pregnancies with borderline amniotic fluid index. Arch Gynecol Obstet. 2007; 276:17-19.

24. Banks EH, Miller DA. Perinatal risks associated with borderline amniotic fluid index. Am J Obstet Gynecol. 1999; 180: 1461-1463.

25. Baron C, Morgan MA, Garite TJ. The impact of amniotic fluid volume assessed intrapartum on perinatal outcome. Am J Obstet Gynecol. 1995; 173:167-174.

26. Akhter H, Guha K, Daisy KP. Amniotic fluid index in high risk pregnancies and pregnancy outcome. Dinajpur Med Col J. 2010; 3:1-5.

27. Petrozella LN, Dashe JS, Mclntire DD, Leveno KJ. Clinical significance of borderline amniotic fluid index and oligohydramnios in preterm pregnancy. Obstet Gynecol. 2011; 117:338-342. 
28. Luo X, Huang Y, Liang R. Analysis of 196 cases of trial of labor with borderline oligohydramnios assessed by ultrasound. Zhonghua Fu Chan KeZaZhi. 1988; 33:585-587.

29. Locatelli A, Zagarella A, Toso L, Assi F, Ghidini A, Biffi A. Serial assessment of amniotic fluid index in uncomplicated term pregnancies: prognostic value of amniotic fluid reduction. J Matern Fetal Neonatal Med. 2004; 15:233-236.

30. Sowmya K. Effect of isolated oligohydramnios in otherwise normal term pregnancy. Int $\mathrm{J}$ Biomed Res. 2015; 5(2):98-101.

31. Al-Bayatti MM. Amniotic fluid index as a predictor of perinatal outcome in patients with prolonged pregnancy. Iraqi J Comm Med. 2008; 3:216-9.

32. Casey Brian M, Donald D. McIntire. Pregnancy outcomes after antepartum diagnosis of oligohydramnios at or beyond 34 weeks' gestation. Am J Obstet Gynaecol. 2000 Apr; 182(4):909-12.

33. Zhang J, Troendle J. Isolated oligohydramnios is not associated with adverse perinatal outcome. Int $\mathrm{J}$ Gynaecol Obstet. 2004 Mar; 3:220-5.

34. Golan A, Lin G. Oligohydramnios maternal complications and fetal outcome in 145 cases. Gynaecol Obstet Invest. 1994; 37(2):91-5.

35. Ekin A, Gezer C, Taner CE, Ozeren M. Perinatal outcomes in pregnancies with oligohydramnios after preterm premature rupture of membranes. J Matern Foetal Neonatal Med. 2015; 28(16):1918-22.
36. Naveiro-Fuentes M, Puertas Prieto A, Ruiz RS, Carrillo Badillo MP, Ventoso FM, Gallo Vallejo JL. Perinatal outcomes with isolated oligohydramnios at term pregnancy. J Perinat Med. 2016; 44(7):793-98.

37. Leibovitch L, Kuint J, Rosenfeld E, Schushan-Eisen I, Weissmann-Brenner A, Maayan-Metzger A. Short term outcome among term singleton infants with intrapartum oligohydramnios. Acta Paediatr. 2012; 101(7):727-30.

38. Magann EF, Chauhan SP, Martin JN. Oligohydroamnios at term and pregnancy outcome. Foetal Matern Med Review 2001; 12:209-227.

39. Nargis N, Begum F. Oligohydramnios at third trimester and perinatal outcome. Bangla J Med Sci 2012; 11:3336.

40. Ahmad $\mathrm{H}$, Munim $\mathrm{S}$. Isolated oligohydramnios is not an indicator for adverse perinatal outcome. J Pak Med Assoc 2009; 59: 691-694.

41. Singhal SR, Gupta R, Sen J. Low Amniotic fluid index as a predictor of adverse perinatal outcome - An Indian perspective. Clinics Mother Child Health 2015; 12:201.

42. Fahmida M, Rumana N, Rumana A, Tahmina B, Kayum $A$, Mohshina $A$, et al. Low amniotic UID index and the materno-fetal out come in 3rd trimester of pregnancy. Bangladesh Med J. 2015 Jan; 44 (1): 16-20.

\begin{tabular}{|c|c|c|c|}
\hline \multicolumn{4}{|c|}{ AUTHORSHIP AND CONTRIBUTION DECLARATION } \\
\hline Sr. \# & Author(s) Full Name & Contribution to the paper & Author(s) Signature \\
\hline 2 & $\begin{array}{l}\text { Nadia Sharif } \\
\text { Ayesha Qasim }\end{array}$ & $\begin{array}{l}\text { Manuscript writing, Critical } \\
\text { analysis, Reference writing } \\
\text { Data collection, Review of } \\
\text { literature. }\end{array}$ & $\begin{array}{l}\text { Uhdiablaip } \\
\text { Ayeshadaniv }\end{array}$ \\
\hline
\end{tabular}

